\title{
Ecological Industry: A Sustainable Economy Developing Pattern
}

\author{
Jingfu Guo, Haijun Mao \& Tingrui Wang \\ School of Economy \& Management, Dalian Nationalities University \\ Dalian 116600, China \\ E-mail: drguo@dlnu.edu.cn
}

This paper is sponsored by Social Science Research Program of the Education Ministry (08JA850002)

This paper is sponsored by the Fundamental Research Funds for the Central Universities (DC10030206)

This paper is sponsored by Liaoning Social Science Planning Program(L09BJL014)

\begin{abstract}
The traditional linear industries led to dwindling resources and even exhaustion, as well as worsening pollution, it is a short-sighted unsustainable developing mode of the economy. Ecological industry is to realize the harmonious development between economy and environment by planning industrial systems according to material cycle in the natural ecological system. The Eco-industry coordinates discrete enterprises and industries and integrates them into optimized industrial ecology chains which establish the "resources - products renewable resources" of the circular economy mode. This paper conducts comprehensive comparison between traditional industry and eco-industry in 10 areas, such as guiding ideology, resource utilizing, environment protection etc. The core essence of the eco-industrial system is the layer of material circulation and delivery of energy use, it is a new, sustainable economic developing model.
\end{abstract}

Keywords: Ecological industry, Environment pollution, Sustainable development

\section{Introduction}

Since 1960s, global environment pollution and ecology destruction have been more and more serious following the industrialization and growth of the world economy. The conflict between industrial undertakings and the world environment is more severe than before. People have begun to rethink and review traditional values and development concepts, realizing that the traditional economic development model will only aggravate the predatory exploitation of resources and seriously damage the environment. People should look for a new development mode based on the broadened horizons of economy, society, science, resource and environment that create harmony between them in the development process. The sustainable development strategy cannot follow the traditional model with large input, high consumption and serious pollution; it must turn into small input, low consumption and light pollution. The environment economists bring forward the circular economy as the new development model requiring people to utilize natural resources and environment capability in a resources-conserving and environment friendly way. It will result in the eco-type transformation of economic structures and industrial ecology into a circular economy at the industry level reflected in industrial development of the advanced stage.

Industrial ecology is the science of economic systems based on knowledge of the structure and function of societal and ecological environments. Industry eco-system is strongly application-oriented and multidisciplinary. It comprises consideration of supply and use of energy and materials, understanding of technologies and engineered systems, basic science, economics, law, management, as well as social sciences. Many terms have been used in the past by various authors to describe the contribution of industrial eco-system to ecologic and economical sustainability. For example, Allenby assigned industrial eco-system the very broad definition, "science of sustainability" (Allenby 1999). This classification is persuasive at first glance, but to some extent misleading when following the argumentation of Wilderer (2007b). A more comprehensive discussion of industrial eco-system contribution to ecologic sustainability is presented by Manahan (1999) who proposed that the goal of industrial ecology is to realize sustainability as a means to achieve "the basis for a much more sustainable global industrial system compared to the one that now exists". The highly acclaimed work of Frosch and Gallopoulos (1989) suggests that the focus of industrial eco-system is "to develop a more closed industrial eco-system, one that is more sustainable". This implies the need to shift from linear (open loop) to multiple use of natural resources, to create cascading energy flows and a closed loop flow of materials, that is to develop ecological industry.

Ecological industry is to realize the harmony development between economy and environment by planning industrial systems according to material cycle in the natural ecological system. It has grown rapidly both in 
theories and practices since 1990s. Many countries including China have applied industrial ecology to industrial practices. It is deeply recognized that developing ecological industry is an important way to realize sustainable development. An industrial symbiosis net could be formed by exchanging by-products and wastes, cascading utilization of energy and waste water, and sharing infrastructure among system units. Different processes correlate each other with material flows, energy flows, money flows and information flows. An eco-industrial system has more complicated resource utilization models and more closed interrelationship in comparison with a common industrial system. This paper firstly conducts comprehensive comparison between traditional industry and the eco-industry in many areas, then does the research on ecological industry basic essence, and discusses the ecological industry as a new, sustainable economy developing model.

\section{The Comparison between Traditional and Ecological Industry}

Environmental pollution, ecological destruction and inefficient depletion of resources in time and space apparently are the largest source of eco-environmental damage by industrial activities. Human economic activities, by consequence, produce great amounts of waste which nature cannot digest or absorb. The predatory traditional industrial economy obtains resources from the environment and generates, in the process of production and consumption, waste discharged into the environment causing a loss of function of the economic system. The system is incomplete; the environment can not function as a black box of inexhaustible resources absorbing all emissions and waste. This linear industrial development on the one hand led to dwindling resources and even exhaustion; on the other hand it leads to worsening pollution. The limited resources and the environment become more "limited", so traditional linear industry is a short-sighted unsustainable development mode of the economy (see FIg 1.).

Based on the principles of the eco-system of coexistence, reduction (reducing), reuse (reusing) and resource regeneration (resourcing), taking material recycling and energy echelon use as its object, Eco-industry coordinates discrete enterprises and industries and integrates them into a optimized industrial ecology chains to form integration, the formation of industrial clusters establishes the "resources - products - renewable resources" of the circular economy mode. Pollution externalities can be set into the inner loop, achieving a rational allocation of resources and economy, natural and social benefit are optimized. Ecosystem evolution from lower to higher process, the material conversion technologies between industrial economy and the natural environment, recycling scale and coordination of cooperation between enterprises are also improving. When the ecosystem resource consumption and environmental emission fully meet the environmental carrying capacity, the proportional relationship between the speeds of resource consumption, waste accumulation, and purification attains a level of sustainable development to achieve the ideal industry eco-system (as Fig. 2).

In the following 10 areas, we conduct comprehensive comparison between traditional industry and the eco-industry.

\section{Ecological industry: A Sustainable Developing Pattern}

From the eco-industrial development evolution, it is not difficult to see that industrial ecology has the characteristics of both natural science and social science. The core essence of the eco-industrial system is the layer of material circulation and delivery of energy use, not only to solve environmental problems, more to solve the problem of scarcity of resources or resources of economic efficiency, that is, resources of the correct disposal (Effective) and efficient use (Efficiency) problem. The main body of the eco-industrial system is industry; its development connotation is the economical efficiency of resource application and adaptation to environment. It is essentially the evolution of resource division and its ultimate goal is harmony between industry (economic activities) and natural environment and sustainable development of industry. In the eco-industrial system, enterprises rely on regional coexistence cooperation, resource's efficient use to transfer a traditional liner production line into a feedback cycling mode, from a separating mode into an integrated cycling mode between industry and environment.

This kind of industry is conducive to completely change the current way of extensive economic growth mode, to achieve economic, ecological and social benefits of organic unity. Therefore, the ecological industry is a new, sustainable economic developing model.

"Market failure" and "government failure" are the economic and institutional causes of ecological imbalance. Short of support in policy, law and code becomes another obstacle to industrial ecology. Government is the coordinator of the public interests, the overall interests and long-term interests, and bears responsibilities for sustainable development of society through the establishment and improvement of industrial ecology in laws, regulations, industrial policies, institutional norms and incentives. Government should guide the behavior of businesses and consumers, promote green technologies and industries, encourage the implementation of the 
eco-system.

\section{References}

Allenby BR. (1999). Industrial ecology: policy framework and implementation. Prentice Hall, Englewood Cliffs, NJ.

Debra L. Code. (2001). A system approach towards managing industrial organic wastes: A case study of cocounut production in St.Lucia, west indies, Master degree paper on resource and environmental studies in Dalhousie University, Halifax, Nova Scotia, Canada: 13-14.

Frosch RA, Gallopoulos NE. (1989). Strategies for manufacturing. Waste from one industrial process can serve as the raw materials for another--thereby reducing the impact of industry on the environment. Sci $\mathrm{Am}$ 261(9):94-102.

Wilderer PA. (2007b). Sustainable water resources management: the science behind the scene. Sustain Sci 2:1-4.

Table 1. Comparison between traditional industry and the eco-industry

\begin{tabular}{|c|c|c|c|}
\hline No. & Categories & Traditional industry & Eco-industry \\
\hline 1 & Guiding ideology & $\begin{array}{l}\text { mass production; rapid incensement; } \\
\text { mechanical law }\end{array}$ & $\begin{array}{ll}\text { sustainable and } & \text { harmonious } \\
\text { development; ecology law }\end{array}$ \\
\hline 2 & Targets & maximum of economic benefits & $\begin{array}{l}\text { coordinated development of economy, } \\
\text { society and nature }\end{array}$ \\
\hline 3 & Resource utilizing & $\begin{array}{l}\text { large mining, Heavy discharging, low } \\
\text { utilizing }\end{array}$ & $\begin{array}{l}\text { low mining, fully utilizing, } \\
\text { little discharging }\end{array}$ \\
\hline 4 & $\begin{array}{l}\text { Industry } \\
\text { structure }\end{array}$ & linear, rigidity, little cooperation & $\begin{array}{l}\text { network, adjusting } \\
\text { circulating cooperation }\end{array}$ \\
\hline 5 & Industry function & $\begin{array}{l}\text { product service, } \\
\text { responsible for sale market }\end{array}$ & $\begin{array}{l}\text { Ecology service, responsible for } \\
\text { product life-circle }\end{array}$ \\
\hline 6 & $\begin{array}{l}\text { Corporation } \\
\text { relation }\end{array}$ & competition emphasis & cooperation, symbiosis \\
\hline 7 & $\begin{array}{l}\text { Environment } \\
\text { protection }\end{array}$ & $\begin{array}{l}\text { terminal recovery, high input, no } \\
\text { repay }\end{array}$ & $\begin{array}{l}\text { clean production, } \\
\text { controlling, little input }\end{array}$ \\
\hline 8 & Waste disposing & $\begin{array}{l}\text { discharge to environment, pollution } \\
\text { recovery external }\end{array}$ & $\begin{array}{l}\text { system inner resource, pollution } \\
\text { recovery interior }\end{array}$ \\
\hline 9 & $\begin{array}{l}\text { Management } \\
\text { efficiency }\end{array}$ & working efficiency & resource and environment effective \\
\hline 10 & $\begin{array}{l}\text { Consumption } \\
\text { ideas }\end{array}$ & large consumption, dissipation & ecological and green consumption \\
\hline
\end{tabular}

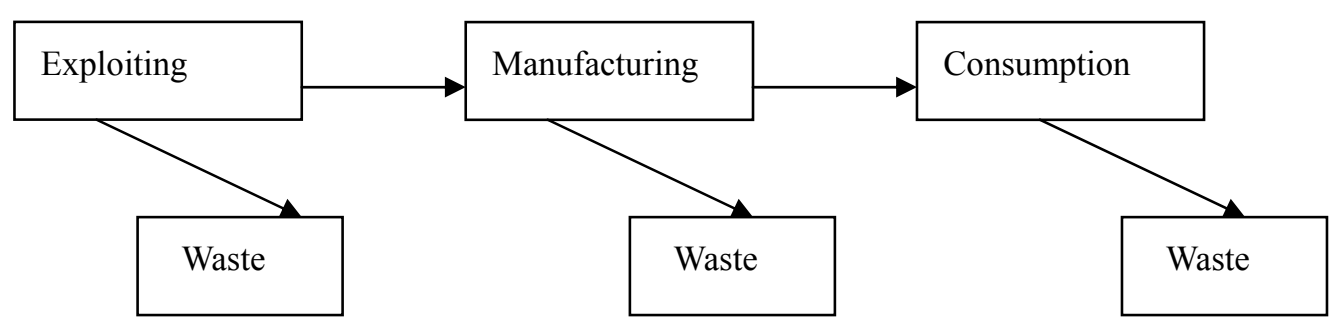

Figure 1. Traditional linear industry model

Resource: Debra L. Code (2001) 


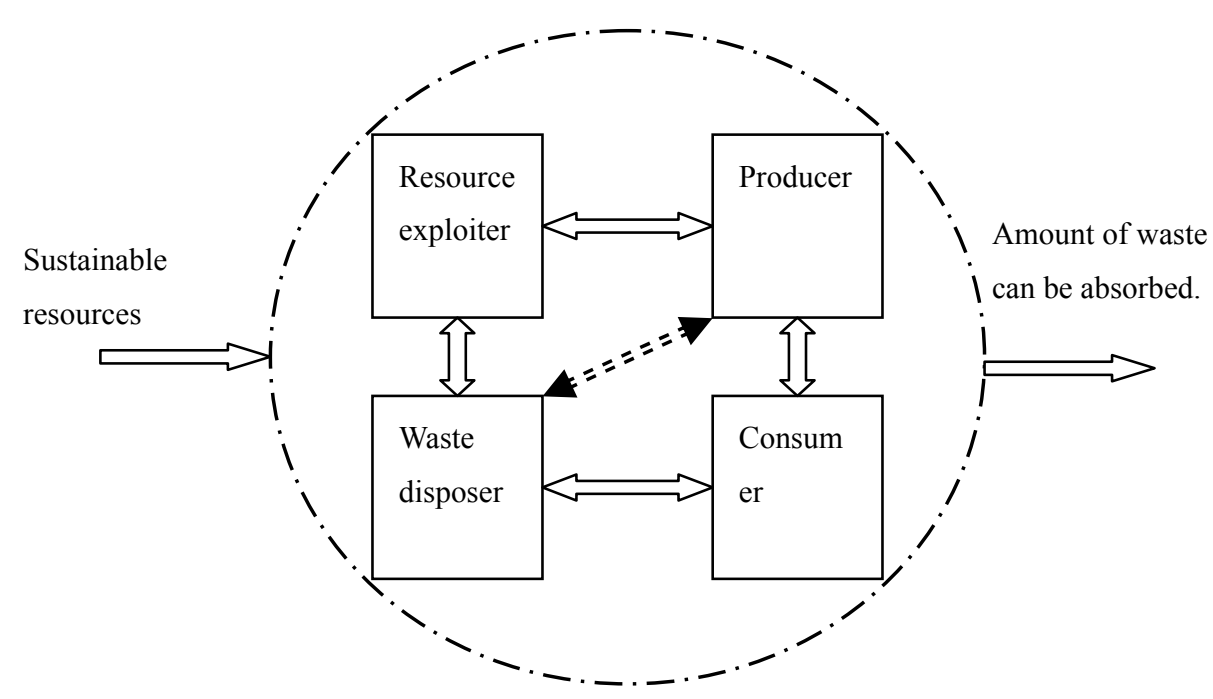

Figure 2. Ideal eco-industry system

Traditional Perspective Industrial Ecology Perspective

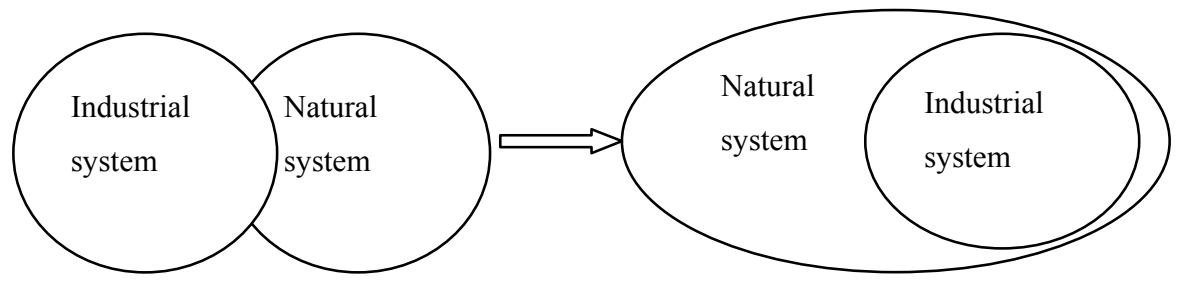

Figure 3. Industry evolution 